\title{
III.
}

Arbeiten aus dem Laboratorium für experimentelle Pharmakologie zu Strassburg.

\section{Ueber die Ernährung des arbeitenden Froschherzens.}

$$
\text { Von }
$$

\author{
Dr. med, et phil. A. Heffter, \\ Assistent am pharmakologischen Institut zn Leipzig.
}

Bei der grossen Wichtigkeit, die das Froschherz für pharmakologische Untersuchungen erlangt hat, erschien es nicht unwesentlich, festzustellen, bei welcher Ernährung dasselbe die höchste Leistungsfähigkeit zeigt, und welche Bestandtheile des Blutes für seine grösste Leistung nothwendig sind. Da sich die Arbeitsleistung eines Herzens aus der Grösse der einzelnen Pulse und der Frequenz seiner Contractionen zusammensetzt, so sind in den nachfolgenden Versuchen beide bestimmt worden. Ausserdem ist auch bei jedem Herzen die "absolute Kraft" ") ermittelt worden, d. h. diejenige Belastung, welche im Momente der Contraction auf den Muskel einwirkend, seine Verkülzung verhindert.

Dass die Herzmusculatur nur mit Hülfe frischen Nährmaterials zu functioniren vermag, und dass ein mit physiologischer Kochsalzlösung getulltes Herz in Diastole stillsteht, aber wieder zu arbeiten beginnt, wenn man es mit $\mathbf{0}$-haltiger Blutflissigkeit durchspült, lehrten Kronecker und Stirling ${ }^{2}$ ). Später gab dagegen MeGuire ${ }^{3}$ ) an, dass der Sauerstoffgehalt der Speiseflussigkeiten für das Herz gleichgiiltig zu sein scheine, da sowohl entgastes Serum, als auch entgastes Blut kräftige Pulsationen unterhielten. Im Anschluss hieran suchte Martius ${ }^{4}$ ) die Frage zu beantworten, welche organischen

1) Dreser, Archiv f. exp. Path. u. Pharm. XXIV. Bd. S. 221.

2) Festgabe für Carl Ludwig. 1875.

3) Du Bois' Archiv f. Physiologie. 1878. S. 321.

4) Ebenda. 1882. S. 542. 
Stoffe der Herzmuskel unmittelbar zu assimiliren und in Arbeit umzusetzen vermag. Er fand, dass Pepton, Glykogen, Syntonin, Eiereiweiss, Casein und Myosin keinerlei ernährende Eigenschaften hätten, dagegen wohl Blut, Lymphe und Serum, dass also nur den serumalbuminhaltigen Fliussigkeiten die Fähigkeit zukäme, das Herz zur Arbeit zu befähigen. Aus seinen Versuchen zieht er folgende Schltisse: „Das Herz leistet niemals auf Kosten der eigenen Substanz Arbeit. Der Muskel kann nur so lange functioniren, als ihm die Möglichkeit geboten ist, die zur Arbeit nöthigen Spannkräfte während und gleichzeitig mit der Thätigkeit einer ihn umspülenden Ernährungsflussigkeit zu entnehmen."

v. Ott ${ }^{1}$ ) benutzte infolge der von Martius gefundenen Thatsachen das Froschberz gewissermaassen als Reagens auf Serumalbumin und reihte den ernährenden Flüssigkeiten noch Chylus, Molke und Milch an, indem er bemerkt, dass Milch ebensolche Curven giebt, wie Blut und Serum.

Obwohl bereits früher schon $\mathrm{Klug}{ }^{2}$ ) gelegentlich darauf hingewiesen hatte, dass sauerstoffreiches Blut die Herzthätigkeit viel intensiver gestaltet als Serum, so schien es doch nach diesen Versuchen, als ob die Sauerstoffzufuhr für die Herzernährung unwesentlich sei. $\mathrm{Ye} \mathrm{o}^{3}$ ) zeigte nun, dass das Herz ohne freien Sauerstoff nicht in vollkommener Weise functioniren könne. Der Sauerstoffverbrauch des thätigen Herzmuskels sei so constant grösser, als der des ruhenden, dass es sicher erscheine, dass während der Contraction das Sauerstoffbedürfniss des Gewebes merklich wachse. Dagegen fand S. Handler ${ }^{4}$, dass die Zehrung des freien Sauerstoffs in keinem Zusammenhang stehe mit der Leistung des Herzens, d. h. die Pulse waren vor und nach der Reduction des Hämoglobins gleich hoch. Die Verfasserin schliesst demnach in Uebereinstimmung mit M c Guire, dass der Sauerstoffverbrauch für die Arbeit des Muskels unnöthig sei.

Gegen alle eben erwähnten Versuche lässt sich einwenden, dass das Herz mit der zu untersuchenden Nährflüssigkeit viel zu kurze Zeit arbeitete, dass die Füllung sich nicht, wie es im Körper geschieht, nach jeder Diastole erneuerte, und dass eine genaue Messung der geleisteten Arbeit nicht möglich war.

1) Du Bois' Archiv f. Physiologie. 1883. S. 1.

2) Ebenda. 1879. S. 465.

3) Journ. of Physiol. Vol. VI. p. 93. 1885.

4) Zeitschr. f. Biol. XXVI. Bd. S. 233. 1890. 
Bei den von mir angestellten Untersuchungen war dagegen ein in lebhafter regelmässiger Thätigkeit befindliches Herz in einen künstlichen Kreislauf eingeschaltet, in dem die verschiedenen Nährflïssigkeiten, deren Einfluss auf die Arbeitsleistung des Herzmuskels untersucht werden sollte, unbeschränkte Zeit circuliren konnten.

Diese Arbeitsleistung und die absolute Kraft habe ich in meinen Versuchen am Williams'schen Apparat gemessen, dessen Einrichtung und Handhabung ich als bekannt voraussetze. ${ }^{1}$ ) Hier sei nur Folgendes erwähnt. Als Normalnahrung, bei der zunächst an jedem Herzen die Arbeit gemessen wurde, benutzte ich nach dem Vorgange von Dreser ${ }^{2}$ ) defibrinirtes, filtrirtes Kalbs- oder Rinderblut mit 2 Theilen 0,6 proc. Kochsalzlösung verdiunnt. Wenn das Herz mit constanter Frequenz arbeitete, wurde die optimale Belastung aufgesucht und während des ganzen Versuches beibehalten. Die Messung der von jedem Pulse geförderten Blutmenge oder das Pulsvolum wurde entweder durch Wägung der von 10 Contractionen geförderten Blutmenge oder durch Ablesung der Flüssigkeitsschwankung des Kochsalzbades, in dem das Herz schlägt, bestimmt. Nach Feststellung der absoluten Kraft des Herzens waren sodann die 3 Zahlen gewonnen, die zur Vergleichung dienen, und es wurde nun durch die zu priffende Nährflüssigkeit das Blut aus dem Apparate und dem Herzen verdrängt. Er weist sich diese nun wirklich als befähigt, das Herz zu ernähren, d. h. nimmt das Pulsvolum nicht innerhalb weniger Minuten bis zum völligen Verschwinden $a b$, so ist es nothwendig, längere Zeit - ungefähr 30 Minuten - zu warten, bis man wieder die Ablesungen macht. Ich habe wiederholt beobachtet, dass eine Veränderung der Ernährung als Reiz auf das Herz wirkt, dass in der ersten Zeit die Frequenz beschleunigt oder verlangsamt wird, und dass bedeutende Schwankungen im Pulsvolum eintreten. Erst wenn das Herz sich an die veränderte Nährfluissigkeit gewöhnt hat, wenn längere Zeit hindurch Frequenz und Pulsvolum gleich bleiben, kann man zur endgültigen Messung schreiten. Dass man nach Feststellung der absoluten Kraft einige Zeit warten und das Herz sich erholen lassen muss, bevor man ein constantes Pulsvolum erbält, hat schon $D$ urdufi ${ }^{3}$ ) erwähnt.

Zunächst habe ich verschiedene Verdünnungsgrade des Rinderbluts und einige andere Blutarten untersucht.

1) Vgl. Archiv f. exp. Path. u. Pharm XIII. Bd. S. 1 und XXIV. Bd. S. 221.

2) a. a. O. S. 224.

3) Archiv f. exp. Path. u. Pharm. XXV. Bd. S. 441. 
I. Temporariaherz. Die Normalbeobachtung (bei Ernährung mit 1 Rinderblut, 2 Kochsalzlösung) ergab die

absolute Kraft . . $\mathrm{H}=48 \mathrm{~cm}$ Blutsäule

Pulsvolum . . . $\mathrm{P}=2,3$ Scalentheile

Frequenz . . . Fr. $=36$ in der Minute.

Bei Ernährung mit 1 Blut und 5 Kochsalzlösung

absolute Kraft . . $\mathrm{H}=46,5 \mathrm{~cm}$

Pulsvolum . . . . $\mathrm{P}=2,4$ Scalentheile

Frequenz . . . Fr. $=34$ in der Minute.

II. Temporariaherz. Normal ernährt

absolute Kraft . . $\mathrm{H}=54,5 \mathrm{~cm}$

Pulsvolum . . . . $\mathrm{P}=3,8$ Scalentheile

Frequenz . . . Fr. $=39$.

Ernährt mit 1 Blut und 9 Kochsalzlösung.

$$
\begin{aligned}
& \mathrm{H}=51 \mathrm{~cm} \\
& \mathrm{P}=3,9 \text { Scalentheile } \\
& \mathrm{Fr} .=36 .
\end{aligned}
$$

III. Temporariaherz. Normal ernährt

$$
\begin{aligned}
& \mathrm{H}=50 \mathrm{~cm} \\
& \mathrm{P}=2,6 \text { Scalentheile } \\
& \mathrm{Fr}=54 .
\end{aligned}
$$

Schwe in e blut ( $1: 3$ verdunnt).

$$
\begin{aligned}
& \mathrm{H}=45 \mathrm{~cm} \\
& \mathrm{P}=2,3 \text { Scalentheile } \\
& \mathrm{Fr}=57 .
\end{aligned}
$$

IV. Temporariaherz. Normal

$$
\begin{aligned}
& \mathrm{H}=56,5 \mathrm{~cm} \\
& \mathrm{P}=2,5 \text { Scalentheile } \\
& \text { Fr. }=57 .
\end{aligned}
$$

Pferdeblut ( $1: 3$ verdünnt).

$$
\begin{aligned}
& \mathrm{H}=60,5 \mathrm{~cm} \\
& \mathrm{P}=3,3 \text { Scalentheile } \\
& \mathrm{Fr}=42 .
\end{aligned}
$$

Nach 2 Stunden: $\mathrm{H}=51 \mathrm{~cm}$

$$
\begin{aligned}
& \mathrm{P}=2,3 \text { Scalentheile } \\
& \mathrm{Fr} .=57 .
\end{aligned}
$$

Diese Versuche lehren, dass eine stärkere Verdünung des Nährmaterials ohne schädlichen Einfluss auf die Arbeitsleistung des Herzens ist, und dass ferner Schweineund Pferdeblut das Herz ebensogut wie Rindsblut zur Arbeit befähigen, Pferdeblut vielleicht noch besser.

Zur Prufung des von Martius gefundenen Versuchsergebnisses untersuchte ich die ernährenden Eigenschaften des Blutserums. Dasselbe wurde aus Rinderblut durch Centrifugiren gewonnen und zeigte eine schwachröthliche Farbe. 
1. Temporariaherz. Normal mit verdünntem Rinderblut ernährt.

$$
\mathrm{H}=51 \mathrm{~cm} \text {. }
$$

10 Pulse fördern bei $25 \mathrm{~cm}$ Belastung 11,2735 Blut.

$$
\mathrm{Fr} .=32 \text {. }
$$

Filtrirtes Rinderblutserum, $\mathrm{H}=35,5$

10 Pulse fördern bei $25 \mathrm{~cm}$ Belastung 10,4013 Serum

$$
\text { Fr. }=30 \text {. }
$$

II. Esculentaherz. Normal $\mathrm{H}=40,5 \mathrm{~cm}$

$$
\mathrm{P}=1,1 \text { Scalentheile }
$$

$\mathrm{Fr}=40$.

Rinderblutserum, $\mathrm{H}=12,5 \mathrm{~cm}$

$\mathrm{P}=0,2$ Scalentheile

Fr. $=34$.

III. Temporariaherz. Normal $\mathrm{H}=46 \mathrm{~cm}$

$\mathrm{P}=1,5$ Scalentheile

$\mathrm{Fr} .=45$.

Rinderblutserum verduinnt $1: 3$.

$$
\begin{aligned}
& \mathrm{H}=20,5 \\
& \mathrm{P}=0,7 \text { Scalentheile } \\
& \mathrm{Fr} .=39 .
\end{aligned}
$$

Nach 40 Minuten wieder normale Ernährung.

$$
\begin{aligned}
& \mathrm{H}=43,5 \mathrm{~cm} \\
& \mathrm{P}=1,4 \text { Scalentheile } \\
& \mathrm{Fr}=42 .
\end{aligned}
$$

IV. Temporariaherz. Normal $\mathrm{H}=47,5 \mathrm{~cm}$

$$
\begin{aligned}
& \mathrm{P}=2,1 \text { Scalentheile } \\
& \mathrm{Fr} .=36 .
\end{aligned}
$$

Serum, verdünnt $1: 3 . \mathrm{H}=12,5 \mathrm{~cm}$

$P=0,8$ Scalentheile

Fr. $=30$.

Nach 40 Minuten normale Ernährung.

$$
\begin{aligned}
& H=46 \mathrm{~cm} \\
& \mathrm{P}=1,4 \text { Scalentheile } \\
& \mathrm{Fr}=42 .
\end{aligned}
$$

Es zeigte sich also, dass das Serum nicht im Stande ist, das Froschherz die gleiche Arbeit leisten zu lassen, wie Blut.

Ganz besonders deutlich zeigt sich diese Thatsache in der bedeutenden Verminderung der absoluten Kraft. Die Pulsvolumina blieben in den ersten Minuten nahezu die gleichen, wie bei normaler Ernährung, nahmen aber constant ab, so dass es scheint, als ob das Serum eine Ermïdung des Herzens nicht aufzuhalten vermag, die dann aber durch zugeftuhrtes Blut wieder gehoben wird.

Es lag nahe, in den rothen Blutkörperchen oder in dem Hämoglobin den hauptsächlichen Factor der Herzthätigkeit zu suchen. Daher wurde zunächst geprüft, wie sich lackfarbenes Blut, in dem die rothen Blutkörperchen zerstört sind, verbielt. 
I. Temporariaherz. Normal $\mathrm{H}=49,5 \mathrm{~cm}$

$\mathrm{P}=2,6$ Scalentheile

Fr. $=44$.

Lackfarbenes Blut, verdünnt $1: 3$.

$$
\begin{aligned}
& \mathrm{H}=12,5 \mathrm{~cm} \\
& \mathrm{P}=0,7 \text { Scalentheile } \\
& \mathrm{Fr}=36 .
\end{aligned}
$$

Nach 45 Minuten Blut durchgeleitet.

$$
\begin{aligned}
& \mathrm{H}=35 \mathrm{~cm} \\
& \mathrm{P}=1,8 \text { Scalentheile } \\
& \text { Fr. }=46 .
\end{aligned}
$$

II. Temporariaherz. Normal H $=47 \mathrm{~cm}$

$$
\begin{aligned}
& \mathrm{P}=3,5 \text { Scalentheile } \\
& \mathrm{Fr}=39 .
\end{aligned}
$$

Lackfarbenes Blut, verdiunt.

$$
\begin{aligned}
& H=26 \mathrm{~cm} \\
& P=1,0 \text { Scalentheile } \\
& F_{r}=33 .
\end{aligned}
$$

Nach 40 Minuten Blut durchgeleitet.

$$
\begin{aligned}
& \mathrm{H}=47 \mathrm{~cm} \\
& \mathrm{P}=3,6 \text { Scalentheile } \\
& \mathrm{Fr}=39 .
\end{aligned}
$$

III. Temporariaherz. Normal $\mathrm{H}=72,5 \mathrm{~cm}$

$$
\mathrm{P}=5,9 \text { Scalentheile }
$$$$
\text { Fr. }=30 \text {. }
$$

Lackfarbenes Blut. $\mathrm{H}=19 \mathrm{~cm}$

$$
\begin{aligned}
& \mathrm{P}=2,8 \text { Scalentheile } \\
& \mathrm{Fr}=36 .
\end{aligned}
$$

Nach 32 Minuten normale Ernährung.

$$
\begin{aligned}
& \mathrm{H}=70 \mathrm{~cm} \\
& \mathrm{P}=3,5 \text { Scalentheile } \\
& \text { Fr. }=39 .
\end{aligned}
$$

IV. Temporariaherz. Normal $\mathrm{H}=66 \mathrm{~cm}$

$$
\mathrm{P}=2,3 \text { Scalentheile }
$$

Fr. $=30$.

Lackfarbenes Blut. $H=20 \mathrm{~cm}$

$$
\mathrm{P}=0,2 \text { Scalentheile }
$$

Fr. $=27$.

Nach 45 Minuten normale Ernährung.

$$
\begin{aligned}
& H=45 \mathrm{~cm} \\
& \mathrm{P}=1,8 \text { Scalentheile } \\
& \text { Fr. }=39 .
\end{aligned}
$$

Also nach Zerstörung der rothen Blutkörperchen ganz die gleiche Erscheinung, wie bei Serumernährung: die Pulsvolumina nehmen ab und besonders wird die absolute Kraft sehr vermindert. Dass aber von einer eigentlichen Schädigung der Herzmusculatur keine Rede ist, beweisen die 
Versuche dadurch, dass es gelang, durch normale Ernäbrung die frühere Leistungsfähigkeit wieder herzustellen.

Um aber genauer zu prüfen, ob freies Hämoglobin wirklich schädlich wirkt, wurde ein Versuch mit einer Hämoglobinlösung von 0,6 Proc. Kochsalzgehalt angestellt.

Temporariaherz. Normal $\mathrm{H}=43 \mathrm{~cm}$

$$
\begin{aligned}
& \mathrm{P}=2,5 \text { Scalentheile } \\
& \mathrm{Fr} .=45 .
\end{aligned}
$$

Hämoglobinlösung. $\mathrm{H}$ nicht messbar

$\mathrm{P}$ nach 8 Minuten $=0,1$ Scalentheile, nach 12 Minuten Stillstand in Diastole.

Durch normale Ernährung belebt sich das Herz rasch.

$$
\begin{aligned}
& \mathrm{H}=43 \mathrm{~cm} \\
& \mathrm{P}=2,1 \text { Scalentheile } \\
& \mathrm{Fr} .=42 .
\end{aligned}
$$

Es ist also eine Giftwirkung nicht wahrnehmbar, die Hämoglobinlösung verhält sich nicht anders, als physiologische Kochsalzlösung, wie aus der sich schnell vollziehenden Erholung des Herzens bei Blutzufubr sich ergiebt.

Das freie Oxyhämoglobin kann, das zeigen die Versuche mit lackfarbenem Blut, an und für sich die Herzmusculatur nicht ernähren; es blieb also zu untersuchen, ob den Blutkörperchen diese Eigenschaft zukommt. Za dem Zwecke wurde Rinderblut centrifugirt, das Serum abgehoben und die Blutkörperchen $2 \mathrm{mal}$ mit 1 proc. Kochsalzlösung in der Centrifuge ausgewaschen. Die zuletzt abgehobene Waschflissigkeit, welche immer klar und farblos war, zeigte bei der Prüfung auf Eiweiss nur eine schwache Opalescenz. Der so erhaltene Brei konnte also nur ganz geringe Spuren von Serumalbumin enthalten. Das ergiebt sich auch aus folgender Ueberlegung. Aus dem mit 2 Theilen Kochsalzlösung: verdünntem Rindsblut setzte sich 1/10 Volum Blutkörperchenbrei beim Centrifugiren $a b$; derselbe enthielt also $1 / 10$ der ursprünglichen Menge Serumbestandtheile. Nachdem das Gefäss mit Kochsalzlösung gefüllt war, setzte sich wieder $1 / 10$ Volumen ab, das nun $1 / 100$ der urspringlichen Menge enthielt, und nach dem zweiten Auswaschen war noch $1 / 1000$ Serummenge im Blutkörperchenbrei enthalten. Das Rinderblut enthält 7 Proc. Albumin, die angewendete Verdünnung also 2,3 Proc. Da nun die Blutkörperchen wieder in 9 Theilen Flüssigkeit suspendirt wurden, um eine Nahrung zu erhalten, die ungefähr ebensoviel davon enthielt, als die normale blutige Kochsalzlösung, so waren in dieser 0,00023 Proc. Serumeiweiss vorhanden. 
I. Temporariaherz. Normal $\mathrm{H}=58 \mathrm{~cm}$

$$
\begin{aligned}
& \mathrm{P}=3,5 \text { Scalentheile } \\
& \mathrm{Fr} .=39 .
\end{aligned}
$$

Blutkörperchen mit Kochsalzlösung (0,6 Proc.), $\mathrm{H}=$ nicht messbar.

Pulsvolumen wird rasch kleiner, nach 15 Minuten $=0,1$ Scalentheil, wobei es längere Zeit verharrt. Frequenz beträgt fast constant 24 .

Nach 45 Minuten normale Ernährung.

$$
\begin{aligned}
& \mathrm{H}=54 \mathrm{~cm} \\
& \mathrm{P}=3,0 \text { Scalentheile } \\
& \mathrm{Fr}=42 . \\
& \mathrm{H}=60 \mathrm{~cm} \\
& \mathrm{P}=3,8 \text { Scalentheile } \\
& \mathrm{Fr}=42 .
\end{aligned}
$$

II. Temporariaherz. Normal $\mathrm{H}=60 \mathrm{~cm}$

Blutkörperchen in Kochsalzlösung. $\mathrm{H}=10 \mathrm{~cm}$.

$P$ nach 2 Min. 0,5 Scalentheile,

$$
\text { Fr. }=36 \text { constant. }
$$

Nach 30 Minuten normale Ernährung.

$$
\begin{aligned}
& \mathrm{H}=51 \mathrm{~cm} \\
& \mathrm{P}=3,0 \text { Scalentheile } \\
& \mathrm{Fr}=39 .
\end{aligned}
$$

Die Blutkörperchen haben also in Kochsalyflüssigkeit nichtdie Fähigkeit, die Herzthätigkeit zu erhalten; zwar schlägt das Herz mit gleichmässiger Pulszahl länger, als mit Hämoglobinlösung, aber die Leistung der einzelnen Contraction ist fast bis auf Null gesunken. Es musste versucht werden, ob in einer Lösung, deren physikalische Beschaffenheit der des Serums einigermaassen ähnlich ist, die Blutkörperchen einen besseren Einfluss zu äussern im Stande wären. Als solche Lösung erschien Hühnereiweiss in entsprechender Verdlinnung geeignet. Wie Martius (a. a. 0.) gefunden hat, ist das Eiereiweiss an sich nicht im Stande, das Herz zu ernähren. Ich habe -selbst noch einige Versuche damit angestellt, von denen einer angefuhrt sei.

Esculentaherz. Normal $\mathrm{H}=40 \mathrm{~cm}$

$$
\begin{aligned}
& \mathrm{P}=2,6 \text { Scalentheile } \\
& \mathrm{Fr} .=48 .
\end{aligned}
$$

Eieralbuminlösung. Das Herz dehnt sich aus. Das Pulsvolum fällt rasch auf 0,2 . Pulszahl unregelmässig. Nach 10 Minuten Stillstand in Diastole. Durch normale Nahrung belebt sich das Herz wieder.

$$
\begin{aligned}
& \mathrm{H}=36 \mathrm{~cm} \\
& \mathrm{P}=2,2 \text { Scalentheile } \\
& \mathrm{Fr}=50 .
\end{aligned}
$$

In dieser Eiweisslösung, die, wie sich zeigte, keine ernährenden Eigenschaften hat, wurden gut ausgewaschene rothe Blutkörper- 
chen rom Rind suspendirt. Man erbält so eine Flissigkeit, die der normalen Nährflüssigkeit im Aussehen sehr ähnlich ist.

I. Temporariaherz. Normal $\mathrm{H}=69 \mathrm{~cm}$

$$
\mathrm{P}=2,9 \text { Scalentheile }
$$

Fr. $=45$.

Eiereiweiss mit Blutkörperchen.

$$
\begin{aligned}
& \mathrm{H}=56 \mathrm{~cm} \\
& \mathrm{P}=3,0 \text { Scalentheile } \\
& \mathrm{Fr} .=44 .
\end{aligned}
$$

Nach 47 Minuten Blut

$$
\begin{aligned}
& \mathrm{H}=65 \mathrm{~cm} \\
& \mathrm{P}=3,1 \text { Scalentheile } \\
& \mathrm{Fr} .=45 .
\end{aligned}
$$

II. Esculentaherz. Normal $\mathrm{H}=35 \mathrm{~cm}$

$P=2,3$ Scalentheile

Fr. $=33$.

Eiereiweiss mit Blutkörperchę.

$$
\begin{aligned}
& \mathrm{H}=34 \mathrm{~cm} \\
& \mathrm{P}=2,1 \text { Scalentheile } \\
& \mathrm{Fr}=27 .
\end{aligned}
$$

Das Herz arbeitet 4 Stunden mit dieser Nahrung.

$$
\text { Dann } \begin{aligned}
\mathrm{P} & \doteq 1,4 \text { Scalentheile } \\
\mathrm{Fr} & =24 .
\end{aligned}
$$

III. Temporariaherz. Normal H $=60 \mathrm{~cm}$

$$
\begin{aligned}
& \mathrm{P}=3,1 \text { Scalentheile } \\
& \mathrm{Fr} .=44 .
\end{aligned}
$$

Eiereiweiss mit Blutkörperchen.

$$
\begin{aligned}
& \mathrm{H}=51,5 \mathrm{~cm} \\
& \mathrm{P}=3,6 \text { Scalentheile } \\
& \mathrm{Fr}=36 .
\end{aligned}
$$

Nach 50 Minuten normale Ernährung

$$
\begin{aligned}
& \mathrm{H}=60 \mathrm{~cm} \\
& \mathrm{P}=3,0 \text { Scalentheile } \\
& \mathrm{Fr} .=42 .
\end{aligned}
$$

Wie diese Versuche lehren, sind die Blutkörperchen in dieser Eieralbuminlösung wohl befähigt, die Ernährung des Herzens zu unterbalten. Es ist allerdings, wie Versuch I und III lehren, die absolute Kraft etwas vermindert, doch ist die Arbeitsleistung ganz die gleiche, wie bei normaler Ernährung.

Es drängte sich nun die Frage auf, ob auch in eiweissfreien Lösungen den Blutzellen eine ernährende Wirkung zukommen wurde. Zur Beantwortung wurde eine 2 proc. Lösung von $\mathrm{Gummi}$ a rabicum verwendet, die sorgfältig mit Natriumcarbonat neutralisirt wurde, und in dieser die Blutkörperchen suspendirt. 
I. Temporariaherz. Normal $\mathrm{H}=39,5 \mathrm{~cm}$

$\mathrm{P}=2,2$ Scalentheile

Fr. $=39$.

Gummilösung mit Blutkörperchen.

$$
\begin{aligned}
& \mathrm{H}=39 \mathrm{~cm} \\
& \mathrm{P}=2,3 \text { Scalentheile } \\
& \mathrm{Fr}=30 . \\
& \mathrm{P}=2,5 \text { Scalentheile } \\
& \mathrm{Fr}=24 .
\end{aligned}
$$

Nach 1 stïndiger Arbeit $\mathrm{P}=2,5$ Scalentheile

II. Temporariaherz. Normal $\mathrm{H}=46 \mathrm{~cm}$

$$
\begin{aligned}
& \mathrm{P}=4,3 \text { Scalentheile } \\
& \text { Fr. }=36 .
\end{aligned}
$$

Gummilösung mit Blutkörperchen.

$$
\begin{aligned}
& \mathrm{H}=42 \mathrm{~cm} \\
& \mathrm{P}=4,7 \text { Scalentheile } \\
& \text { Fr. }=36 .
\end{aligned}
$$

Nach 1 stïndiger Arbeit $\mathrm{P}=4,5$ Scalentheile

$$
\mathrm{Fr} .=36 \text {. }
$$

III. Temporariaherz. Normal $\mathrm{H}=50 \mathrm{~cm}$

$$
\begin{aligned}
& \mathrm{P}=1,7 \text { Sealentheile } \\
& \text { Fr. }=36 .
\end{aligned}
$$

Gummilösung mit Blutkörperchen.

$$
\begin{aligned}
& \mathrm{H}=48 \mathrm{~cm} \\
& \mathrm{P}=2,0 \text { Scalentheile } \\
& \mathrm{Fr} .=24 .
\end{aligned}
$$

IV. Esculentaherz. Normal $\mathrm{H}=46 \mathrm{~cm}$

$$
\begin{aligned}
& P=3,1 \text { Scalentheile } \\
& \text { Fr. }=42 .
\end{aligned}
$$

Trummilösung mit Blutkörperchen.

$$
\begin{aligned}
& \mathrm{H}=47 \mathrm{~cm} \\
& \mathrm{P}=3,5 \text { Scalentheile } \\
& \mathrm{Fr} .=36 .
\end{aligned}
$$

Es zeigte sich in diesen Versuchen, dass anch in eiweiss. freien Lösungen die Blutzellen vorzüglieh zur Erbaltung der Herzthätigkeit geeignet sind. Die Gummilösung scheint sogar ein besseres Medium als die Eiweisslösung zu sein, $\mathrm{da}$ in allen Versuchen auch die absolute Kraft unverändert geblieben ist. Das Pulsvolumen ist bei allen Versuchen etwas vermehrt, die Frequenz fast immer ein wenig vermindert, so dass die in der Zeiteinbeit geförderte Blutmenge ebenso gross sein wird, wie bei normaler Ernährung.

Schliesslich seien einige Versuche angefuhrt uber den Einfluss von Pepton auf die Contraction des Herzmuskels. Eine Lösung von Pepton (Pepton. siceum Grubler) in physiologischer Kochsalzlösung bringt das Herz in sehr kurzer Zeit zum Still- 
stand, obne es aber zu schädigen, da bei zugeführter normaler Ernährung es dann ganz wie vorher arbeitet. Diese Lősung verbält sich nicht anders als gewöhnliche Kochsalzlösung. Löst man dagegen das Pepton in verdïnntem Rinderblut, so zeigen sich folgende Veränderungen.

I. Temporariaherz. Normal $\mathrm{H}=64,5 \mathrm{~cm}$

$\mathrm{P}=4,4$ Scalentheile

Fr. $=42$.

Normalnahrung mit 1 Proc. Pepton.

$$
\begin{aligned}
& \mathrm{H}=49 \mathrm{~cm} \\
& \mathrm{P}=2,5 \text { Scalentheile } \\
& \mathrm{Fr} .=48 .
\end{aligned}
$$

Nach 43 Minuten peptonfreie Nahrung.

$$
\begin{aligned}
& \mathrm{H}=47 \mathrm{~cm} \\
& \mathrm{P}=2,0 \text { Sealentheile } \\
& \mathrm{Fr} .=48 .
\end{aligned}
$$

II. Temporariaherz. Normal $\mathrm{H}=70 \mathrm{~cm}$ $P=2,7$ Scalentheile Fr. $=60$.

Normalnahrung mit 2 Proc. Pepton.

$$
\begin{aligned}
& \mathbf{H}=22,5 \mathrm{~cm} . \\
& \mathbf{P}=2,0 \text { Scalentheile } \\
& \mathrm{Fr} .=45 .
\end{aligned}
$$

Nach 2 Stunden Stillstand in Diastole.

Durch Zufuhr von peptonfreier Nahrung wird das Herz wiederbelebt.

$$
\begin{aligned}
& \mathrm{H}=30 \mathrm{~cm} \\
& \mathrm{P}=1,5 \text { Scalentheile } \\
& \mathrm{Fr}=54 .
\end{aligned}
$$

Die peptonhaltige Nahrung war demnach nicht im Stande, das Herz zur vollen Kraftentfaltung zu veranlassen, die absolute Kraft war sehr vermindert, ebenso auch das Pulsvolum. Es hatte sogar den Anschein, als ob eine dauernde Schädigung des Herzens bewirkt würde, da es nicht gelang, durch Zufuhr von Normalnahrung die frühere Arbeitsleistung wieder herzustellen. Doch liess sich der Einwand erbeben, dass zunächst schon die starke Concentration der Nährflissigkeit dem Herzen schädlich sein könnte. Oben ist nun gezeigt worden, dass auch eine stärker verdünnte Blut-Kochsalzlösung (1:10) im Stande ist, das Herz ausreichend zu ernäbren. Zu einer solchen wurde Pepton zugesetzt und damit eine Lösung erhalten, deren Concentration nicht grösser war, als die der normalen Nabrung.

III. Temporariaherz. Blut $1: 10$ verdünnt

$$
\begin{aligned}
& \mathrm{H}=51 \mathrm{~cm} \\
& \mathrm{P}=3,9 \text { Scalentheile } \\
& \mathrm{Fr}=36 .
\end{aligned}
$$


Dieselbe Nahrung mit 2 Proc. Pepton. Nach 5 Minuten $\mathbf{P}=0,3$, nach 8 Minuten Stillstand. Durch Zufuhr von Normalnahrung wird das Herz wieder arbeitsfähig.

$$
\begin{aligned}
& \mathrm{H}=50 \mathrm{~cm} \\
& \mathrm{P}=3,9 \text { Scalentheile } \\
& \text { Fr. }=36 .
\end{aligned}
$$

Eine Blut-Kochsalzlösung von gleieher Verdünnung mit 1 Proc. Pepton bringt innerhalb 10 Minuten das Herz wieder zum Stillstand.

Peptonfreie Nahrung belebt wieder.

$$
\begin{aligned}
& \mathrm{H}=48 \mathrm{~cm} \\
& \mathrm{P}=3,8 \text { Scalentheile } \\
& \mathrm{Fr} .=36 .
\end{aligned}
$$

Diese letzten Versuche zeigen, dass das Pepton in der That giftig ist, und dass es nicht die Concentration der Lösung war, welche in den beiden ersten Versuchen einen schädlichen Einfluss ausübte. In jenen mag die längere Zeitdauer, in welcher das Herz mit dem Pepton in Berührung war, auch eine dawernde Schädigung bewirkt haben, während es im letzten Versuch gelang, das Herz immer wieder zu seiner früheren Action zu veranlassen.

Aus den geschilderten Versuchen ergiebt sich Folgendes:

Blut mit physiologischer Kochsalzlösung verdunnt, vermag das arbeitende Frosebherz sehr gut zu ernähren; ob das Blut rom Rind, Pferd oder Schwein stammt, ob der Verdtinnangsgrad verschieden ist, der Effect bleibt sich ganz gleich: es wird in der Zeiteinheit dieselbe Arbeit geleistet.

Anders verhält sich das Serum, wie die Versuche zeigen. Unter dem Serum-Regime ist das Herz nieht im Stande, die gleiche Arbeit zu leisten, wie bei Bluternährung, es ermudet offenbar sehr rasch, wie sich aus dem verminderten Pulsvolum, noeh mehr aber aus der herabgesetzten Leistungsfähigkeit des Herzmuskelquersehnittes ergiebt. Die auftretenden Erscheinumgen exinnern ganz an die Kohlensäurewirkung, wie sie Dreser ') besebreibt, wobei ebenfalls absolute Kraft und Pulsvolumen gleichzeitig abnehmen.

Da sich bei lackfarbenem B lat die gleichen Erscheinungen zeigten und sich ausserdem ergab, dass eine eigentliche Giftwirkang des gelösten Hämoglobins niebt angenommen werden konte, so muss hierans geschlossen werden, dass es die rothen Blutkörperchen sind, welche vorzugsweise das Herz zur Arbeit befähigen, und dass zur vollkommenen Function Sauerstoff ein unbedingtes nothwendiges Erforderniss ist. Es zeigte sict zunächst, dass die rothen Blut-

1) Archiv f. exp. Path. u. Pharm. XXIV. Bd. S. 235. 
körperchen in Kochsalzlösung nicht im Stande waren, die Herzarbeit zu unterhalten, dass vielmehr noch eine zweite Bedingung zu erfüllen war, eine Flïssigkeit von bestimmter physikal is cher, dem Serum ähnlicher Beschaffenheit herzustellen. Nachdem dies auf zweierlei Art gelungen war, arbeitete das Herz in völlig normaler Weise, so dass also die künstlich hergestellte Nährflüssigkeit mit dem Blute ganz gleichwerthig war. Dieses iberraschende Resultat steht mit dem von Martius anfgestellten Satze, dass nur serumalbuminhaltige Flüssigkeiten das Herz zu ernähren vermögen, in directem Widerspruch. Es müssen vielmehr die rothen Blutzellen als die hauptsächlichsten Factoren der Herzaction betrachtet werden. 